\title{
Radiotherapy for pituitary adenomas: long-term outcome and complications
}

\author{
Chai Hong Rim, MD, Dae Sik Yang, MD, Young Je Park, MD, Won Sup Yoon, MD, \\ Jung Ae Lee, MD, Chul Yong Kim, MD \\ Department of Radiation Oncology, Korea University Medical Center, Seoul, Korea
}

\begin{abstract}
Purpose: To evaluate long-term local control rate and toxicity in patients treated with external beam radiotherapy (EBRT) for pituitary adenomas.

Materials and Methods: We retrospectively reviewed the medical records of 60 patients treated with EBRT for pituitary adenoma at Korea University Medical Center from 1996 and 2006. Thirty-five patients had hormone secreting tumors, 25 patients had non-secreting tumors. Fifty-seven patients had received postoperative radiotherapy (RT), and 3 had received RT alone. Median total dose was $54 \mathrm{~Gy}$ (range, 36 to $61.2 \mathrm{~Gy}$ ). The definition of tumor progression were as follows: evidence of tumor progression on computed tomography or magnetic resonance imaging, worsening of clinical sign requiring additional operation or others, rising serum hormone level against a previously stable or falling value, and failure of controlling serum hormone level so that the hormone level had been far from optimal range until last follow-up. Age, sex, hormone secretion, tumor extension, tumor size, and radiation dose were analyzed for prognostic significance in tumor control.

Results: Median follow-up was 5.7 years (range, 2 to 14.4 years). The 10-year actuarial local control rates for non-secreting and secreting adenomas were $96 \%$ and $66 \%$, respectively. In univariate analysis, hormone secretion was significant prognostic factor $(p=0.042)$ and cavernous sinus extension was marginally significant factor $(p=0.054)$ for adverse local control. All other factors were not significant. In multivariate analysis, hormone secretion and gender were significant. Fifty-three patients had mass-effect symptoms (headache, dizziness, visual disturbance, hypopituitarism, loss of consciousness, and cranial nerve palsy). A total of 17 of 23 patients with headache and 27 of 34 patients with visual impairment were improved. Twenty-seven patients experienced symptoms of endocrine hypersecretion (galactorrhea, amenorrhea, irregular menstruation, decreased libido, gynecomastia, acromegaly, and Cushing's disease). Amenorrhea was abated in 7 of 10 patients, galactorrhea in 8 of 8 patients, acromegaly in 7 of 11 patients, Cushing's disease in 4 of 4 patients. Long-term complication was observed in 4 patients; 3 patients with cerebrovascular accident, 1 patient developed dementia. Of these patients, 3 of 4 received more than $60 \mathrm{~Gy}$ of irradiation.

Conclusion: EBRT is highly effective in preventing recurrence and reducing mass effect of non-secreting adenoma. Effort to improve tumor control of secreting adenoma is required. Careful long-term follow-up is required when relatively high dose is applied. Modern radiosurgery or proton RT may be options to decrease late complications.
\end{abstract}

Keywords: Pituitary adenoma, Radiotherapy, Prognostic factors, Complications

Received 29 March 2011, Revised 18 April 2011, Accepted 8 June 2011.

Correspondence: Chul Yong Kim, MD, Department of Radiation Oncology, Korea University Medical Center, 126-1 Anamdong, Seongbuk-gu, Seoul 136-705, Korea. Tel: +82-2-920-5516, Fax: +82-2-927-1419, E-mail: kcyro@korea.ac.kr

(c) This is an Open Access article distributed under the terms of the Creative Commons Attribution Non-Commercial License (http://creativecommons.org/ licenses/by-nc/3.0/) which permits unrestricted non-commercial use, distribution, and reproduction in any medium, provided the original work is properly cited. www.e-roj.org 


\section{Introduction}

Pituitary adenomas are common benign tumors that may cause visual defects, hypopituitarism, and respective endocrine symptoms, constitute about $10 \%$ of all adult intracranial neoplasms [1]. Asymptomatic adenomas may be found frequently, with incidence of $10 \%$ radiologically in normal population and as many as $20 \%$ in autopsy findings $[2,3]$. Treatment options for patients with pituitary adenomas vary depending on clinical situations and have changed with improvements in radiologic imaging, surgical techniques, radiation therapy and the medical approach including dopamine agonists and somatotropine. Transsphenoidal resection is considered as primary treatment of choice for non-prolactin secreting pituitary adenomas [4], as well as medical treatment commonly with bromocriptine for prolactin secreting pituitary adenomas.

External beam radiotherapy (RT) is essential part of successful management preventing recurrence and reducing symptoms. RT produced long-term tumor control rates with either postoperatively or radically, usually from 80-97\% [5-7]. The incidence of complications has been reported acceptable, but the morbidity can be severe. Brain tumors (mainly meningiomas and high-grade astrocytomas) may be occurred after RT with incidence of $2 \%[6,8,9]$. Damage to optic apparatus is rare with conventional RT scheme, while most cases reported are in patients treated with relatively higher dose (>50 Gy) or greater fraction (>2 Gy) [8]. Some authors showed increased hazard of cerbrovascular accident after

Table 1. Patient characteristics

\begin{tabular}{lc}
\multicolumn{1}{c}{ Characteristics } & Value \\
\hline Gender & \\
Male & $28(46.7)$ \\
Female & $32(53.3)$ \\
Age (yr) & $43(16-78)$ \\
Hormone secreting & \\
Secreting & $35(58.3)$ \\
Non-secreting & $25(41.7)$ \\
Tumor extension beyond sella & \\
None & $8(13.3)$ \\
Suprasella extension & $46(76.7)$ \\
Cavernous sinus extension & $29(48.3)$ \\
Sphenoid sinus extension & $10(16.7)$ \\
Not accessible & $5(8.3)$ \\
Tumor size $\left(\mathrm{cm}^{2}\right)$ & $6.25(0.6-37.5)$ \\
\hline
\end{tabular}

Values are presented as number (\%) or median (range).
RT $[5,10]$. Hypopituitarism has occupied most common late complication of RT with occurrence of $20-80 \%$ [7,8,10-12].

Pituitary adenomas are benign tumors usually have long natural history, so that proper evaluation of treatment outcomes requires long-term follow-up. This study examines our experience in the treatment of pituitary adenoma to assess both long-term control rate and the complication of RT. We also investigated improvement of patient symptoms and prognostic factors.

\section{Materials and Methods}

Patients characteristics are summarized in Table 1. From 1996 to 2006, 70 patients who had pathologically confirmed or clinically diagnosed pituitary adenomas were referred to radiation oncology department at Korea University Medical Center. Ten patients were excluded for following reasons; Follow-up period less than 2 years (6 patients), incomplete RT with far lower received dose than prescribed (4 patients). Of the remaining 60 patients, 57 patients received RT after surgery, while the remaining 3 patients treated with RT alone.

We divided these 60 patients into 2 groups, those with nonsecreting adenomas (35 patients), and those with secreting adenomas (25 patients). Endocrinological findings were considered as primary criteria to determine which hormone the tumors were secreting and whether tumors were nonsecreting or secreting. Pathologic results were used as secondary references to confirm the classification or to aid categorization of tumors with equivocal serum hormone level. Secreting tumors were further divided into prolactinsecreting-adenomas (18 patients), growth-hormone secretingadenomas (9 patients), adrenocorticotrophic-hormonesecreting adenomas (4 patients), and 3 patients had tumors secreting both prolactin and growth-hormone.

Computed tomography (CT), magnetic resonance imaging (MRI), plain skull radiograph and respective script were used as references to evaluate tumor extension and size. Assessment of tumor extension and size was possible in 55 patients with pre-treatment radiologic findings. Extension and size of the tumors at the last follow-up were also recorded in 38 patients.

\section{Treatment}

Of the 60 patients who received RT at our institution, 3 patients treated with RT alone and 57 patients underwent surgery and postoperative RT (Table 2). Between the 57 patients who received preceding surgery, 5 patients had 
Table 2. Treatment methods

\begin{tabular}{lc}
\hline & Patients (\%) \\
\hline Postoperative radiotherypy & $57(95)$ \\
Salvage radiotherypy & $3(5)$ \\
Method of surgery & \\
Transsphenoidal approach & $55(91.7)$ \\
Open craniotomy & $5(8.3)$ \\
\hline
\end{tabular}

transcranial tumor removal, and in the remaining 52 patients, operation with transsphenoidal approach was performed. We evaluated residual tumor status after surgical resection through imaging methods (CT and MRI) and operation records. Total resection was defined as no evidence of residual disease with post-operative study. All of the 57 patients who received operation prior to RT were assessed as subtotal resection.

All patients were treated with once-a-day megavolatage radiation therapy, five fractions per week, 3-field technique (One antero-superior oblique field and two lateral fields), with 4-10 MV linear accelerator (Clinac 1800 or Clinac 600 c, Varian, Palo Alto, CA, USA). Simulation, shielding to shape the fields, and port films were used routinely. Field size were varying from $16 \mathrm{~cm}^{2}$ to $49 \mathrm{~cm}^{2}$ (median, $25 \mathrm{~cm}^{2}$ ) depending on tumor extent. The common field sizes were $5 \times 5 \mathrm{~cm}$ square in 35 patients, $6 \times 6 \mathrm{~cm}$ square in 12 patients. Median tumor dose was $54 \mathrm{~Gy}$ (range, 32.4 to $61.2 \mathrm{~Gy}$ ). The tumor dose was $32-36$ Gy in 3 patients (5\%), 45-57.6 Gy in 38 patients (63\%) and $>60$ Gy in 19 patients (32\%). Three patients who received radiation with dose less than 36 Gy did not completely finished the prescribed RT schedules. Three patients received RT without prior operation were given 50.4, 54, 61.2 Gy, respectively. Relatively higher dose of irradiation (above $60 \mathrm{~Gy}$ ) were administered to patients with comparably large adenomas or extensive extension.

Eighteen of 21 patients with prolactin-secreting adenoma underwent bromocriptine therapy, 11 of 13 patients with growth-hormone-secreting adenoma treated with bromocriptine and octreotide either during or after RT.

\section{Follow-up and evaluation of treatment result}

All patients had a minimum 2 years of potential follow-up period. Times of follow-up were measured from the date of patients initiated RT. The length of follow-up period were ranged from 2 to 14.4 years (median, 5.6 years). The follow-up data was obtained from RT records and hospital charts. Posttreatment test included neuro-opthamological examination, endocrine evaluation and radiologic assessment. Pre-treatment tumor size was calculated by multiplying the longest diameter by the longest perpendicular diameter on the maximally sliced image from CT or MRI.

Patients were considered to have treatment failure if they met one or more of the following criteria; Evidence of tumor progression on follow-up CT or MRI, aggravation of clinical signs or symptoms which requires salvage operation or RT, rise in the serum level of respective hormone against a previously stable or falling value, and failure of controlling serum hormone level so that the hormone level had been far from normal range until last follow-up.

\section{Statistical methods}

Acturial curves of the proportion of patients with treatment failure were generated with the method of Kaplan and Meier [13]. Patients who have not experienced treatment failure were censored at the time of their last follow-up. Patients considered to meet any criteria of treatment failure were recorded as events at the time of recurrence. In case of patients who never achieved normal value of respective hormone, we considered the patients to have failed at the time of last follow-up. Multivariate analysis of prognostic factors is performed with Cox regression analysis.

Differences in tumor control rates with respect to individual baseline variables were assessed using the log-rank test [14]. In calculating cause-specific survival, deaths due to symptom of pituitary adenoma and/or treatment complication were classified as cause-specific, and those clearly unrelated with pituitary adenoma were censored.

\section{Results}

\section{Clinical symptoms related to pituitary adenomas}

Presenting symptoms and follow-up status are described in Table 3. Fifty-three patients including all of 35 non-secreting pituitary adenoma patients had symptoms related to masseffects. Twenty-three cases of headache, 34 cases of visual disturbance, 3 cases of hypopituitarism, 3 cases of loss of consciousness and 3 cases of cranial nerve palsy were present before treatment. A total of 27 of 34 patients with visual disturbance and 17 of 23 patients with headache improved. All patients who experienced loss of consciousness and cranial nerve palsy showed relief of symptoms.

Clinical symptoms of secreting adenomas were present in 27 patients. Ten cases of amenorrhea, 8 cases of galactorrhea, 11 
Table 3. Evaluation of symptoms

\begin{tabular}{lcc}
\hline & $\begin{array}{c}\text { No. of } \\
\text { patients }\end{array}$ & $\begin{array}{c}\text { Improved after } \\
\text { therapy (\%) }\end{array}$ \\
\hline $\begin{array}{c}\text { Total no. of patients with } \\
\text { 'mass-effect' symptoms }\end{array}$ & 53 & \\
Headache & 23 & $17(74)$ \\
Visual disturbance & 34 & $27(79)$ \\
Cranial nerve palsy & 3 & $3(100)$ \\
Loss of consciousness & 3 & $3(100)$ \\
Others (hypopituitarism) & 3 & \\
Total no. of patients with & 27 & \\
'hormone-related'symptoms & & \\
Amenorrhea & 10 & $7(70)$ \\
Galactorrhea & 8 & $8(100)$ \\
Acromegaly & 11 & $7(64)$ \\
Cushing's disease & 4 & $4(100)$ \\
Diminished libido & 2 & $2(100)$ \\
Gynecomastia & 1 & $0(0)$ \\
\hline
\end{tabular}

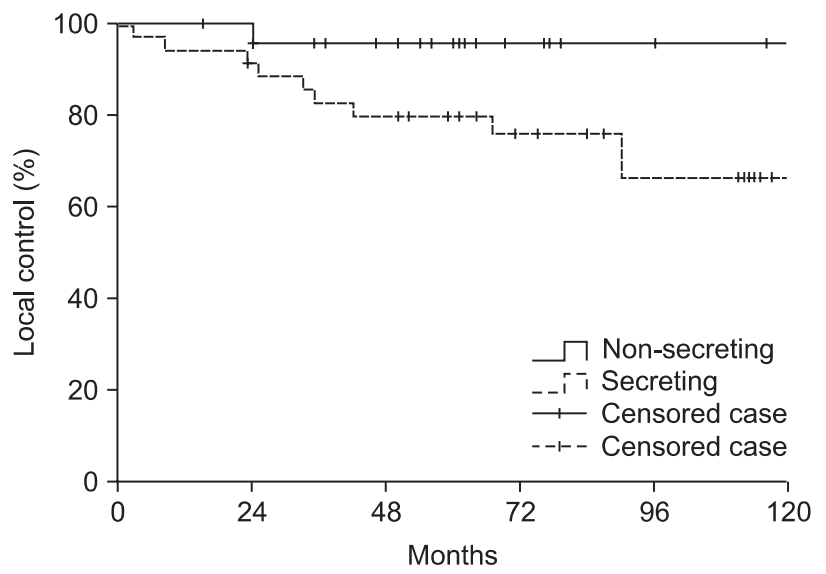

Fig. 1. Local control analysis of 60 patients with pituitary adenoma according to hormone-secreting status. Local control rate was significantly higher in non-secreting tumor subgroup ( $p$ $=0.042$ ).

cases of acromegaly, 4 cases of Cushing's disease, 2 cases of diminished libido and 1 case of gynecomastia was recorded before initiation of treatment. Improvements were experienced by 7 of 10 patients with amenorrhea, 8 of 8 with galactorrhea, 7 of 11 with acromegaly, 4 of 4 with Cushing's disease and 2 of 2 with diminished libido. One patient with gynecomasitia was unchanged in symptom.

\section{Local control and prognostic factors}

Fig. 1 illustrates the local control rates for secreting and nonsecreting tumor type. The 10-year tumor control rates for non-secreting and secreting adenomas were 96\% and 66\%,
Table 4. Univarite analysis for local control

\begin{tabular}{|c|c|c|c|}
\hline Prognostic factor & $\begin{array}{l}\text { Patients } \\
\text { (n) }\end{array}$ & $\begin{array}{c}\text { 10-year } \\
\text { control rate } \\
(\%)\end{array}$ & p-value \\
\hline Tumor type & & & 0.042 \\
\hline Non-secreting & 25 & 95.8 & \\
\hline Secreting & 35 & 66.4 & \\
\hline Gender & & & 0.061 \\
\hline Male & 32 & 63.4 & \\
\hline Female & 28 & 88.1 & \\
\hline Age (yr) & & & 0.56 \\
\hline$<50$ & 38 & 71.9 & \\
\hline$\geq 50$ & 22 & 85.2 & \\
\hline Suprasellar extension & & & 0.143 \\
\hline Yes & 45 & 70.8 & \\
\hline No & 9 & 100 & \\
\hline $\begin{array}{l}\text { Cavernous sinus } \\
\text { extension }\end{array}$ & & & 0.053 \\
\hline Yes & 28 & 63.9 & \\
\hline No & 26 & 88 & \\
\hline $\begin{array}{l}\text { Sphenoid sinus } \\
\text { extension }\end{array}$ & & & 0.266 \\
\hline Yes & 10 & 44.4 & \\
\hline No & 44 & 84.3 & \\
\hline Total tumor dose (Gy) & & & 0.456 \\
\hline$\leq 54$ & 40 & 69.9 & \\
\hline$>54$ & 20 & 83.6 & \\
\hline
\end{tabular}

respectively ( $p=0.042$ ). Eleven patients experienced failure of tumor control, 10 with secreting adenomas and 1 with a non-secreting adenoma. Of these 11 patients, 5 patients with secreting adenomas failed to achieve stable status of respective hormone level from the initiation of treatment to the last follow-up, other 4 patients with secreting adenomas considered as recurrence due to elevated hormone level from previously controlled hormone status, and 2 patients experienced aggravation of symptom and showed radiologic evidence of progression. Salvage operation was performed in 2 patients.

Univariate analysis of prognostic factors related to local control are summarized in Table 4. Whether the adenoma was secreting or non-secreting was the most significant prognostic factor for local control, and the cavernous sinus extension was marginally significant prognostic factor ( $p$ $=0.053)$. Age, sphenoid sinus extension, radiation dose, surgical methods, and radiologic complete remission were not significant prognostic factors. All patients who experienced recurrence showed suprasellar extension in initial radiologic findings though it was not statistically significant ( $p=0.14)$. 
Table 5. Univarite analysis for local control

\begin{tabular}{cccc}
\hline Factors & p-value & $\begin{array}{c}\text { Hazard } \\
\text { ratio }\end{array}$ & $\begin{array}{c}95 \% \\
\text { confidential } \\
\text { interval }\end{array}$ \\
\hline $\begin{array}{c}\text { Non-secreting vs. } \\
\text { secreting }\end{array}$ & 0.015 & 13.3 & $1.6-106.4$ \\
$\begin{array}{c}\text { Female vs. male } \\
\text { Cavernous sinus } \\
\text { extension (-) vs. (+) }\end{array}$ & 0.018 & 5 & $1.3-19.3$ \\
\hline
\end{tabular}

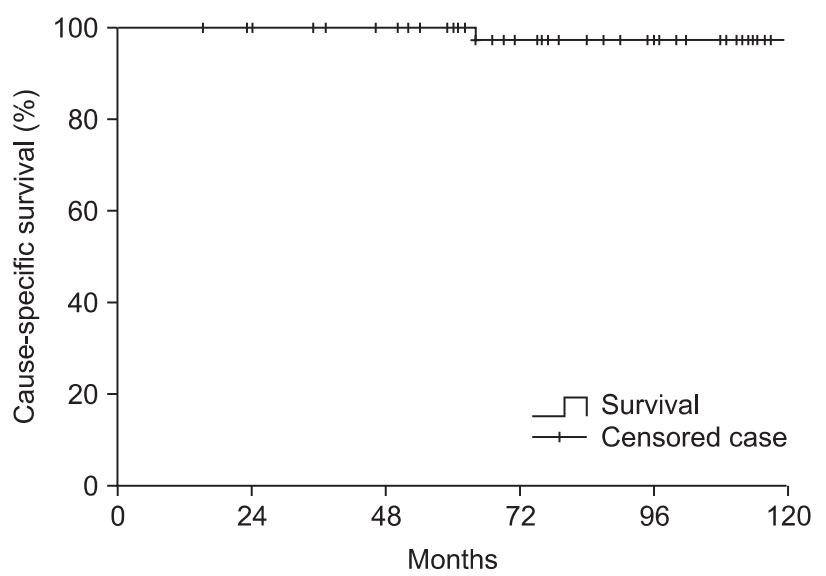

Fig. 2. Cause-specific survival of 60 patients including both nonsecreting and secreting tumor groups. The 10 year cause-specific survival was 98\%. No statistically significant difference was found between secreting tumor group and non-secreting tumor group.

In multivariate analysis, hormone secretion ( $p=0.015)$ and gender were significant $(p=0.018)$. Results are summarized in Table 5 .

\section{Survival}

The 10 year cause-specific survival rate was 98\% (Fig. 2), and the overall 10 year survival rate was 93\% for patients including both non-secreting and secreting tumor (Fig. 3). There was no statistically significant difference between non-secreting and secreting tumor group with regard to cause-specific survival and overall survival. The deaths of 4 patients were identified. The cause of deaths were malignant tumors (2 patients), cerebrovascular accidents (2 patients). Among 2 patients who were expired due to other malignancy, one patient who had non-secreting pituitary adenoma causing bitemporal hemianopsia received operation and post-operative irradiation of $48.6 \mathrm{~Gy}$, died due to carcinoma peritonei with unknown primary origin 37 months after the initiation of RT. The other patient who also had non-secreting tumor received salvage

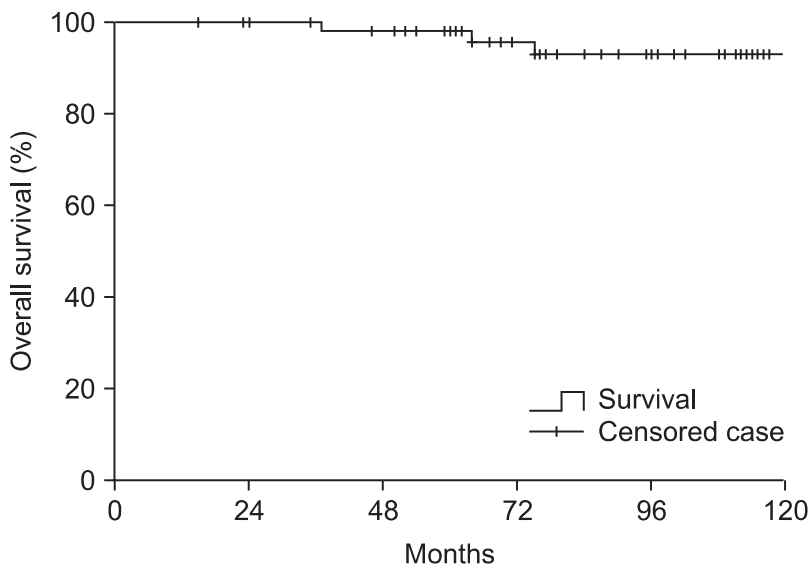

Fig. 3. Overall survival of 60 patients including both nonsecreting and secreting tumor groups. The 10 year overall survival was 93\%. No statistically significant difference was found between secreting tumor group and non-secreting tumor group.

operation and 61.2 Gy dose of radiation due to symptomatic progression after initial operation, deceased due to advanced colon cancer 75 months after RT. In 2 patients who died from cerebrovascular accidents, one patient received operation and 61.2 Gy dose of radiation due to prolactin-secreting tumor, and the other patient treated with operation and postoperative irradiation of 54 Gy had non-secreting adenoma at initial diagnosis. The former patient died 64 months after RT and the latter patient died 133 months after RT.

\section{Side effects of treatment}

Serious neurologic side effect except hypopituitarism were seen in 4 patients (6.7\%). One patient experienced dementia, and 3 patients suffered from cerebrovascular accidents. All 3 patients with cerebrovascular accidents had radiologic evidence that the lesions of infarction were close or in the treatment field of irradiation. No patient had brain necrosis or optic nerve complications. The information of complications and treatment are summarized at Table 6.

Hypopituitarism following surgery and RT is the most common long-term side effect. With exclusion of 10 patients who presented hypopituitarism before the initiation of treatment including both surgery and RT, 38 of 50 patients (76\%) showed hypopituitarism after treatment. Seventeen patients diagnosed as hyperpituitarism after surgery, and 21 patients determined as hypopituitarism after RT. 
Table 6. Radiotherapy (RT)-related complications

\begin{tabular}{|c|c|c|c|c|c|c|c|c|}
\hline $\begin{array}{l}\text { Age before } \\
\text { treatment/ } \\
\text { sex }\end{array}$ & Complication & $\begin{array}{c}\text { Time after RT } \\
\text { (mo) }\end{array}$ & Secreting & $\begin{array}{l}\text { Initial tumor } \\
\text { size }(\mathrm{cm})\end{array}$ & OP method & RT dose (Gy) & $\begin{array}{l}\text { Field size } \\
\quad(\mathrm{cm})\end{array}$ & Status \\
\hline $63 / F$ & Dementia & 50 & No & $3.5 \times 2$ & TSA & 61.2 & $6 \times 6$ & DID \\
\hline $58 / F$ & CVA & 48 & Prolactin & $6.5 \times 5$ & TSA & 61.2 & $10 \times 8$ & $\mathrm{DOC}$ \\
\hline $51 / \mathrm{M}$ & CVA/ICH & 128 & No & $2 \times 2$ & TSA & 54 & $5 \times 5$ & $\mathrm{DOC}$ \\
\hline $62 / F$ & CVA & 84 & Prolactin & $5 \times 5$ & TSA & 61.2 & $6 \times 5$ & NED \\
\hline
\end{tabular}

OP, operation; TSA, trans-sphenoidal approach; DID, dead of intercurrent disease; CVA, cerebrovascular accident; DOC, dead of complication; ICH, intracranial hemorrhage; NED, no evidence of disease.

\section{Discussion and Conclusion}

Most pituitary adenomas are benign [15], in that they develop slowly with long natural history which they cause a long-term affliction. Secreting and non-secreting adenomas may induce various clinical symptoms, including visual disturbance due to mass effect and respective hormonal symptoms. With these clinical problems in mind, we decided to analyze our data of patients who were diagnosed as pituitary adenomas with respect to treatment outcomes.

Reported incidence of treatment failure after surgery alone is variable. Ciric et al. [16] reported recurrence rate of 50\% after subtotal resection and $21 \%$ after total resection. Turner et al. [4] reported 10 -year recurrence free survival rate of $56 \%$ with 65 patients with non-secreting adenoma treated solely with trans-sphenoidal surgery. Gittoes et al. [17] compared treatment outcomes of pituitary adenomas after surgery alone and after surgery and postoperative RT. The 10-year progression free survival rates were 68\% in surgery alone group and 93\% in surgery and postoperative RT group.

Numerous studies have demonstrated that surgery followed by postoperative RT or RT alone offers a high likelihood of long-term control of pituitary adenomas. Snead et al. [7] performed a series with both secreting and non-secreting adenomas including 100 patients. The 10-year local control rates after treatment for non-secreting and secreting pituitary adenomas were 98\% and 73\%, respectively ( $p=0.0015$ ). Sasaki et al. [11] reported the result of 91 patients including secreting and non-secreting adenomas. The tumor control rates at 10 years were $98 \%$ and $83 \%$ for non-secreting and secreting adenomas, respectively $(p=0.006)$.

In our series, the 10-year tumor control rates for nonsecreting and secreting adenomas were 96\% and 66\%, respectively ( $p=0.04)$. With regard to the tumor control rates of non-secreting adenomas, our result of $96 \%$ was comparable to other reported studies. The tumor control rates of $66 \%$ with secreting adenomas were lower than previous studies. However, in our study, all patients had clinically gross disease before RT. We believe that this factor may have contributed to the worse control rates of secretory adenomas, because several investigators have documented that extent of surgical resection is related to tumor control $[11,18,19]$.

In regard of prognostic factors influencing tumor control, Grigsby et al. [6] reported that the total radiation doses greater than 45 Gy as an only significant prognostic factor. McCord et al. [20] denoted that doses greater than 45 Gy showed no benefit on tumor control. Brada et al. [5] and Colin et al. [21] reported secreting type as a prognostic factor. Our results showed that disease type and gender were prognostic in multivariate analysis. Hormone secretion status was mentioned as a prognostic factor in many other previous studies. With regard to result that gender was a significant prognostic factor, it may be due to limitation of small number of patients and retrospective method of our study. The reason for that the total dose not to be prognostic in our study is probably that 57 of 60 patients received more than $45 \mathrm{~Gy}$ of radiation.

As for side effects, cerebrovascular accidents were occurred in 3 patients and 1 patient suffered from dementia. Three of 4 patients received 61.2 Gy of RT and one patient received 54 Gy of RT. There were no cases of secondary tumor or optic nerve palsy. Brada et al. [22] denoted that the dose of RT was an independent prognostic factor of cerbrovascular accidents of treated pituitary adenoma cases. Ono and Maehara [23] reported the rate of brain necrosis with $22.9 \%$ in their Japanese nationwide investigation in 1984. All patients with brain necrosis received 49-60 Gy using one lateral field or lateral opposed field. Stewart et al. [24] reported that radiation may cause intimal thickening of vessel and inflammatory atherosclerotic plaques, subsequently increase the risk of cerebrovascular accident. 
Modern radiosurgery technique has theoretical advantage that the properties to lower the radiation dose of normal tissues. Some authors reported the results of Gamma-knife radiosurgery with comparatively larger patients group [25-27]. Though their series have drawback of relatively shorter followup, no central nervous system (CNS)-related complication were reported in their series. Proton beam RT has notional advantage that the energy deposition occurs with no exit dose beyond the target volume. In 2 modern reports using proton beam radiosurgery with relatively longer follow-up (>60 months), no CNS-related toxicity and excellent local control were reported $[28,29]$.

Hypopituitarism is the most common late complication; the incidence of the complication varies from 22\% to 60\% $[5,12,30,31]$. In our series, hormonal replacement therapy was required in $16.7 \%$ of patients at diagnosis and $63.3 \%$ after treatment. Whether the hypopituitarism was caused by solely $\mathrm{RT}$ is uncertain.

Our results confirmed previously reported efficacy of external beam RT for non-secreting pituitary adenomas. As the local control rate for secreting adenoma was unsatisfactory, we intend to make more effort to improve it. Modern radiosurgery technique may decrease the risk of late complication, and by increasing biologic dose to tumor without hazardous increase of unnecessary irradiation to normal tissue, can provide possibility to increase tumor control. Though the likelihood of severe complication is relatively low, possible increased risk of CNS-related toxicity should be considered when comparatively higher dose is applied.

\section{Conflict of Interest}

No potential conflict of interest relevant to this article was reported.

\section{References}

1. Surawicz TS, McCarthy BJ, Kupelian V, Jukich PJ, Bruner JM, Davis FG. Descriptive epidemiology of primary brain and CNS tumors: results from the Central Brain Tumor Registry of the United States, 1990-1994. Neuro Oncol 1999;1:14-25.

2. Hall WA, Luciano MG, Doppman JL, Patronas NJ, Oldfield EH. Pituitary magnetic resonance imaging in normal human volunteers: occult adenomas in the general population. Ann Intern Med 1994;120:817-20.

3. Muhr C, Bergstrom K, Grimelius L, Larsson SG. A parallel study of the roentgen anatomy of the sella turcica and the histopathology of the pituitary gland in 205 autopsy specimens. Neuroradiology 1981;21:55-65.

4. Turner HE, Stratton IM, Byrne JV, Adams CB, Wass JA. Audit of selected patients with nonfunctioning pituitary adenomas treated without irradiation: a follow-up study. Clin Endocrinol (Oxf) 1999;51:281-4.

5. Brada M, Rajan B, Traish D, et al. The long-term efficacy of conservative surgery and radiotherapy in the control of pituitary adenomas. Clin Endocrinol (Oxf) 1993;38:571-8.

6. Grigsby PW, Stokes S, Marks JE, Simpson JR. Prognostic factors and results of radiotherapy alone in the management of pituitary adenomas. Int J Radiat Oncol Biol Phys 1988;15:1103-10.

7. Snead FE, Amdur RJ, Morris CG, Mendenhall WM. Long-term outcomes of radiotherapy for pituitary adenomas. Int J Radiat Oncol Biol Phys 2008;71:994-8.

8. Roberge D, Shenouda G, Souhami L. Pituitary. In: Halperin EC, Perez CA, Brady LW, editors. Perez and Brady's principles and practice of radiation oncology. 5th ed. Philadelphia: Wolters Kluwer/Lippincott Williams \& Wilkins; 2008. p. 751-64.

9. Lee JY, Park KR, Kim HJ, Lee Cl, Kim MS, Jung SH. Glioblastoma after radiotherapy for pituitary adenoma. J Korean Soc Ther Radiol Oncol 1999;17:287-92.

10. Erridge SC, Conkey DS, Stockton D, et al. Radiotherapy for pituitary adenomas: long-term efficacy and toxicity. Radiother Oncol 2009;93:597-601.

11. Sasaki R, Murakami M, Okamoto $Y$, et al. The efficacy of conventional radiation therapy in the management of pituitary adenoma. Int J Radiat Oncol Biol Phys 2000;47:133745.

12. Tsang RW, Brierley JD, Panzarella T, Gospodarowicz MK, Sutcliffe SB, Simpson WJ. Role of radiation therapy in clinical hormonally-active pituitary adenomas. Radiother Oncol 1996;41:45-53.

13. Kaplan EL, Meier P. Nonparametric estimation from incomplete observations. J Am Stat Assoc 1958;53:457-81.

14. Mantel N. Evaluation of survival data and two new rank order statistics arising in its consideration. Cancer Chemother Rep 1966;50:163-70.

15. Popovic EA, Vattuone JR, Siu KH, Busmanis I, Pullar MJ, Dowling J. Malignant prolactinomas. Neurosurgery 1991;29:127-30.

16. Ciric I, Mikhael M, Stafford T, Lawson L, Garces R. Transsphenoidal microsurgery of pituitary macroadenomas with long-term follow-up results. J Neurosurg 1983;59:395401.

17. Gittoes NJ, Bates AS, Tse $W$, et al. Radiotherapy for nonfunction pituitary tumours. Clin Endocrinol (Oxf) 1998;48:3317. 
18. Greenman $Y$, Ouaknine G, Veshchev I, Reider G II, Segev $Y$, Stern N. Postoperative surveillance of clinically nonfunctioning pituitary macroadenomas: markers of tumour quiescence and regrowth. Clin Endocrinol (Oxf) 2003;58:763-9.

19. Hughes MN, Llamas KJ, Yelland ME, Tripcony LB. Pituitary adenomas: long-term results for radiotherapy alone and post-operative radiotherapy. Int J Radiat Oncol Biol Phys 1993;27:1035-43.

20. McCord MW, Buatti JM, Fennell EM, et al. Radiotherapy for pituitary adenoma: long-term outcome and sequelae. Int J Radiat Oncol Biol Phys 1997;39:437-44.

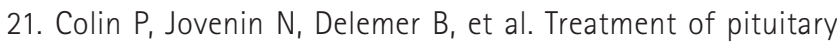
adenomas by fractionated stereotactic radiotherapy: a prospective study of 110 patients. Int J Radiat Oncol Biol Phys 2005;62:333-41.

22. Brada M, Burchell L, Ashley S, Traish D. The incidence of cerebrovascular accidents in patients with pituitary adenoma. Int J Radiat Oncol Biol Phys 1999;45:693-8.

23. Ono Y, Maehara F. Complication of irradiation in brain tumors. Gan No Rinsho 1989;35:1347-53.

24. Stewart FA, Hoving $S$, Russell NS. Vascular damage as an underlying mechanism of cardiac and cerebral toxicity in irradiated cancer patients. Radiat Res 2010;174:865-9.
25. Jagannathan J, Sheehan JP, Pouratian N, Laws ER Jr, Steiner L, Vance ML. Gamma knife radiosurgery for acromegaly: outcomes after failed transsphenoidal surgery. Neurosurgery 2008;62:1262-9.

26. Jezkova J, Marek J, Hana V, et al. Gamma knife radiosurgery for acromegaly: Iong-term experience. Clin Endocrinol (0xf) 2006;64:588-95.

27. Losa M, Gioia $L$, Picozzi $P$, et al. The role of stereotactic radiotherapy in patients with growth hormone-secreting pituitary adenoma. J Clin Endocrinol Metab 2008;93:2546-52.

28. Petit JH, Biller BM, Coen JJ, et al. Proton stereotactic radiosurgery in management of persistent acromegaly. Endocr Pract 2007;13:726-34.

29. Aghi MK, Petit J, Chapman $P$, et al. Management of recurrent and refractory Cushing's disease with reoperation and/or proton beam radiosurgery. Clin Neurosurg 2008;55:141-4.

30. Rush S, Cooper PR. Symptom resolution, tumor control, and side effects following postoperative radiotherapy for pituitary macroadenomas. Int J Radiat Oncol Biol Phy 1997;37:1031-4.

31. Dekkers OM, van der Klaauw AA, Pereira AM, et al. Quality of life is decreased after treatment for nonfunctioning pituitary macroadenoma. J Clin Endocrinol Metab 2006;91:3364-9. 